\title{
A Case of Bilateral Duplicated Ureter - Gross Anatomy
}

\section{Matsuyama $\mathrm{N}^{* 1,2}$}

${ }^{1}$ Department of Human Anatomy \& Pathology, School of Nursing, Japan University of Health Sciences, Japan ${ }^{2}$ Department of Oral Anatomy, Division of Oral Science, Kanagawa Dental University, Japan

${ }^{*}$ Corresponding author: Matsuyama N, Ph.D., Japan University of Health Sciences, Satte 1961-2, Satte -City, Saitama Prefecture, 340-0113 Japan, Fax: +81-480-40-4860, Tel: +81-480-40-4848, E-mail: n-matsuyama@ jhsu.ac.jp

\section{Citation: Matsuyama N (2017) A Case of Bilateral Duplicated Ureter - Gross Anatomy. J Case Rep Stud} 5(6): 601

Received Date: November 07, 2017 Accepted Date: December 27, 2017 Published Date: December 29, 2017

\begin{abstract}
Duplicated ureter is a frequent malformation that occurs in approximately 1 in 20 people. We herein report the detailed case of bilateral duplicated ureter in which two ureters originated from a single renal pelvis and merged just proximal to the ureterovesical junction.
\end{abstract}

Keywords: Duplicated ureter; Bifid ureter; Ureteric bud; Gross anatomy

\section{Introduction}

The kidneys are the main organs of the urinary system. The renal hilum is the entry and exit site for structures servicing the kidneys: vessels, nerves, lymphatics, and ureters.

The renal artery originates from the aorta at the area between L1 and L2, just inferior to the origin of the superior mesenteric artery (SMA). These arteries are typically posterior to the renal veins and anterior to the renal pelvis. The left renal artery arises at a higher level than the right renal artery and follows an upward course, but the right one is longer and passes posterior to the vena cava, with a downward course to the right kidney.

The left renal vein is longer and crosses the midline anterior to the abdominal aorta and posterior to the SMA. This vein receives the left testicular or ovarian vein from below, the left suprarenal vein from above, and the lumbar vein before joining to the inferior vena cava.

There are many anomalies in kidneys. The extra renal artery, duplicated ureter and horseshoe kidney are observed in many cases.

Duplicated ureter is a frequent malformation that occurs in approximately 1 in 20 people. Advances in diagnostic imaging have resulted in an increase in the number of clinical cases reported [1-6]; however, very few studies have reported the gross findings of this condition at autopsy [7-11]. In addition, although there are many reported cases of unilateral double ureter [1-6], few cases of its bilateral counterpart have been reported [7-11].

Duplicated ureter is typically associated with double renal pelvis, and is therefore termed double renal pelvis and ureter. Duplicated ureter is found in $5 \%$ of urinary tract malformations. Two renal pelvises and two ureters entering the bladder separately are referred to as complete duplicated ureter, and two renal pelvises and two ureters that merge just proximal to the ureterovesical junction are referred to as incomplete duplicated ureter. The incidence rate of incomplete duplicated ureteris is three times more than complete duplicated ureter.

In this paper, we report the detailed case of bilateral duplicated ureter in which two ureters originated from a single renal pelvis and merged just proximal to the ureterovesical junction.

\section{Subject and Methods}

The subject was a cadaver (No. 1,896, a 100-year-old woman who died of old age) that had been donated to the Department of Oral 
Anatomy of Kanagawa Dental University for use in gross anatomy dissection in the 2016 academic year, and had been embalmed by injecting a mixture of formaldehyde and ethanol into the left femoral artery.

To facilitate gross examination, the abdominal aorta and inferior vena cava were cut off at a distance of $1 \mathrm{~cm}$ above the origin of the celiac artery, at the bifurcation of the external and internal iliac arteries. The duplicated ureters were cut off at the ureterovesical junction, and the urinary organ system and its vascular system were removed en bloc. In addition, the renal parenchyma was crushed using forceps to examine the anatomical connections between the ureters and renal pelvis.

\section{Results}

Figure 1a shows the urinary organs and their vasculature that were removed en bloc.

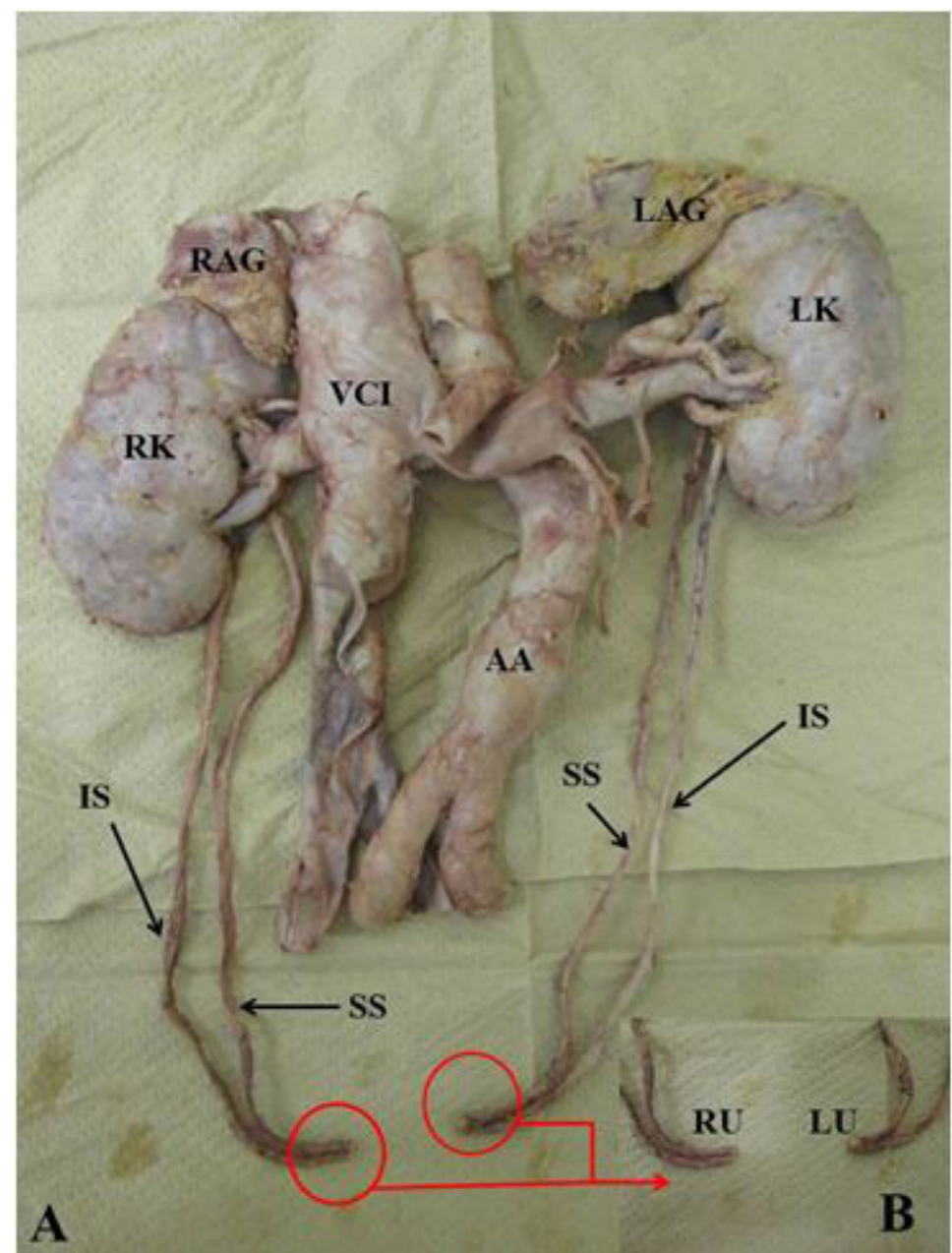

LK: Left kidney; RK: Right kidney; LAG: Left adrenal gland; RAG: Right adrenal gland; VCI: Inferior cava vein; AA: Abdominal aorta; SS: Superior segment; IS: Inferior segment; LU: Left ureter; RU: Right ureter; VCI: Inferior cava vein

Figure 1: (a) The organs removed; (b) Confluence of two ureters

\section{Left duplicated ureter}

The superior segment (SS) running from the renal hilum (simply referred to as the superior segment) measured $210 \mathrm{~mm}$ in length and $5 \mathrm{~mm}$ in diameter, and emptied into the posterior aspect of the bladder. The inferior segment (IS) running from the renal hilum (simply referred to as the inferior segment) measured $190 \mathrm{~mm}$ in length and $4 \mathrm{~mm}$ in diameter, reaching the ureterovesical junction. Duplicated ureters descended without following the Weigert-Meyer law, and merged at $30 \mathrm{~mm}$ below the origin of the left common iliac artery before joining the bladder (Figure 1a, 1b, and 2).

\section{Right duplicated ureter}

The SS measured $220 \mathrm{~mm}$ in length and $5 \mathrm{~mm}$ in diameter, and emptied into the posterior aspect of the bladder. The IS measured $180 \mathrm{~mm}$ in length and $4 \mathrm{~mm}$ in diameter, and reached the ureterovesical junction. Duplicated ureters descended without following the Weigert-Meyer law, and merged at $32 \mathrm{~mm}$ below the origin of the right common iliac artery before joining the bladder (Figure 1a, 1b, and 2). 


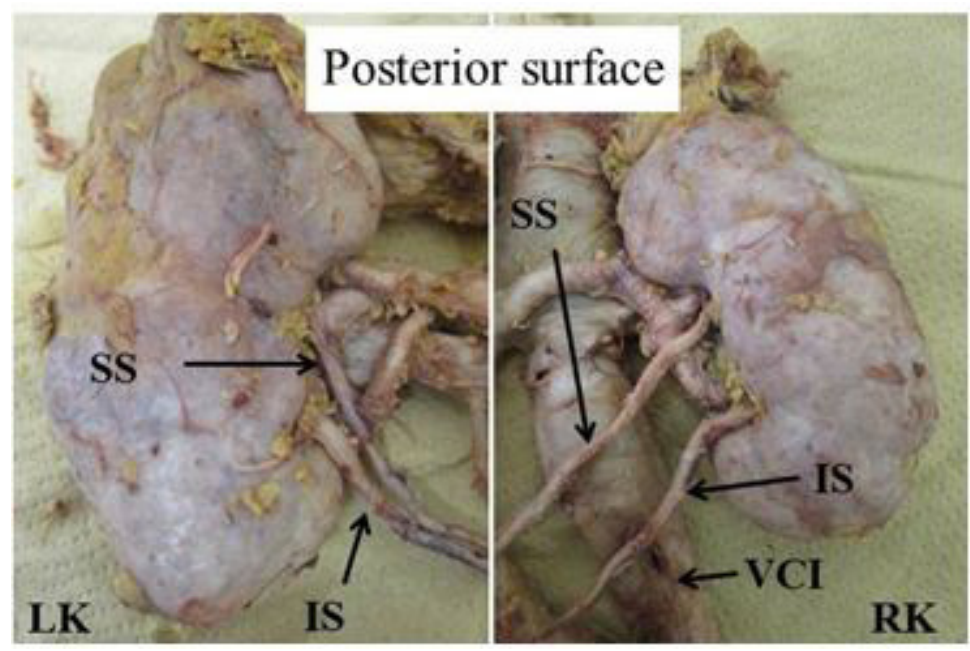

LK: Left kidney; RK: Right kidney; SS: Superior segment; IS: Inferior segment Figure 2: Posterior view of the kidneys and ureters

\section{Bilateral renal pelvises}

Renal pelvises were crushed using forceps, but no bilateral double renal pelvis was observed (Figure 3 ).

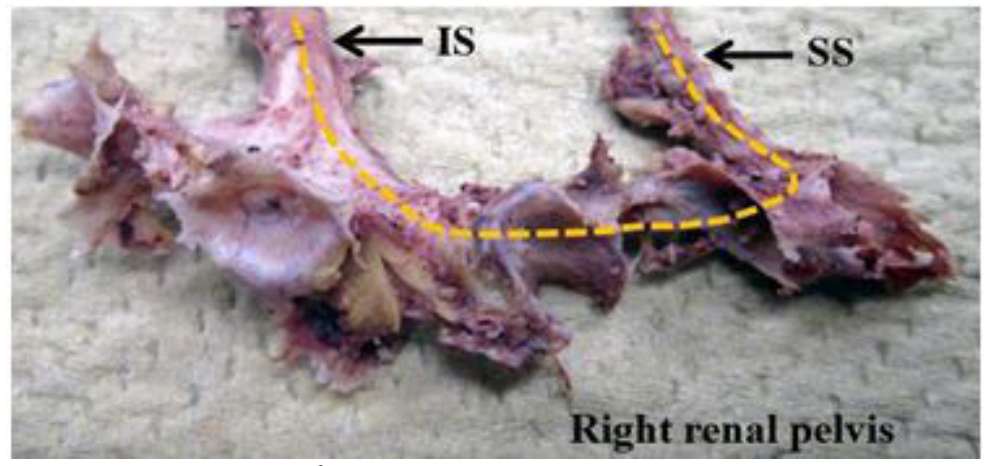

SS: Superior segment; IS: Inferior segment

Figure 3: The renal parenchyma was crushed to dissect the right renal pelvis and duplicated ureters. The yellow dotted line indicates the connection of the renal pelvis and duplicated ureters

\section{Discussion}

Although bilateral duplicated ureters were observed, vessel variations in courses were not found. Bilateral duplicated ureter is the most common anomaly of the renal pelvis and ureter [7-11]. Two types of this anomaly exist. In the complete type [5,6], two superior and two inferior segments empty separately into the bladder [1-4,7-11]. In the incomplete type, two superior and two inferior segments merge to form a Y stem emptying through a single orifice $[8,12]$. In the complete type, the SS opens into the bladder at a lower level than the IS (the Weigert-Meyer law) [13,14].

Embryologically, the complete type results if two ureteric buds arise from the mesonephric duct at 4-5 weeks of intrauterine life. The two ureters cross each other, and the SS enters the bladder more caudally than normal, while the IS opens into the bladder normally or cranially [11]. The incomplete type results if the ureteric bud bifurcates halfway, making the two ureters merge between the renal pelvis and bladder [11].

In the present cadaver, no double renal pelvis was found on either side, and two ureters originated from the pelvis of each kidney (Figure 2 and 3). In addition, without following the Weigert-Meyer law, the two ureters merged just before ending at the ureterovesical junction (Figure 1a and b).

At the end of 5 weeks of human embryonic development, the final adult kidney, referred to as the metanephros, is formed. Around the same time, the ureteric bud forms the collecting ducts, papillary ducts, calyces, renal pelvises, and ureters [11]. If the ureteric bud splits early (after 5 weeks), a double renal pelvis results [11].

This cadaver had single pelvis. The superior segment (SS) was observed upper than middle of renal hilus and the inferior segment (IS) was found lower than middle of renal hilus.

With these observations in view of embryological study, the ureteric bud did not split and formed two ureters on either side. Thus, 
this a rare case of bilateral duplicated ureter in which two ureters merged just proximal to the ureterovesical junction.

Operating surgeons need not only to interpret CT images and MRI images, but also to have deep knowledge about ureter and vascular system around ureter in view of clinical study.

\section{Conclusion}

Double pelvis results if the ureteric bud splits early (after 5 weeks of gestation). In the present cadaver, the ureteric bud did not split and formed two ureters on either side. Thus, this is a rare case of bilateral double ureter in which two ureters merged just proximal to the ureterovesical junction.

\section{Acknowledgments}

Ethical clearance - taken from the "Guidelines of Japanese Society of Anatomy".

\section{References}

1. Bhandarkar AD, Raju AM, Rao MS (1997) Single unilateral ectopic bifid ureter with contralateral orthotopic quadrufid ureter- a rare combination. J post Graduate Med 43: 104-5.

2. Chou CT, Yang AD, Hong YC, Wu HK (2006) Bilateral retrocaval ureters with IVC duplication. Abdom Imaging 31: 596-7.

3. Chang E, Santillan C, O’ Boyle MK (2011) Blind-ending branch of a bifid ureter: multidetector CT imaging findings. Br J Radiol 84: 38-40.

4. Tang M, Wang Q, Liu B, Li J, Lu Q, et al. (2015) Single ectopic ureteral orifice with bilateral duplicated renal collecting systems in an adult girl: Diagnosis by magnetic resonance urography. Can Urol Assoc J 9: 554-8.

5. Neulander E, Kaneti J (1996) Salvage of renal transplant allograft with complete duplication of collectory system by end-to-end and end-to-side pyeloureterostomy. Scand J Urol Nephrol 30: 411-3.

6. Nakatani T, Uchida J, Kim T, Yamamoto K, Kishomoto T (2000) Modified extravesical ureterocystoneostomy of the kidney transplant allograft with completely duplicated ureters. Int J Urol 7: 313-5.

7. Das S, Dhar P, Mehra RD (2001) Unilateral isolated bifid ureter -A case report. J Anat Soc India 50: 43-4.

8. Prakash, Rajini T, Venkatiah J, Bhardwaj AK, Singh DK, et al. (2011) Double ureter and duplex system: a cadaver and radiological study. Urol J 8: 145-8.

9. Ravindra SS, Naveen K, Jyothsna P, Ashwini AP, Anitha G, et al. (2014) Incomplete duplicated (bifid) left ureter - A case report. Sch J Med Case Rep 2: 303-5.

10. Sailaja TK, Rajasree TK (2014) A rare anomaly of ureter and its developmental aspect - a case report. MRIMS J Health 2: 102-4.

11. Deepali KR, Reshma SB (2015) Duplex kidney -An Anatomical and Clinical insight. J Dent and Med 14: 14-7.

12. Chen CL, Tang SH, Cha TL, Meng E, Wu ST Tsao et al. (2014) Combined Y-shaped common channel transureteroureterostomy with Boari flap to treat bilateral long-segment ureteral strictures. BMC Res Notes 7: 550-3.

13. Slaughenhoupt BL, Mitcheson HD, Lee DL (1997) Ureteral duplication with lower pole ectopia to the vas: a case report of an exception to the Weigert-Meyer law Urology 49: 269-71.

14. Jain P, Parelkar S, Shah H, Sanghavi B, Mishra P (2008) Uncrossed complete ureteral duplication with dysplastic lower moiety: a violation of the Weigert-Meyer law. J Pediatr Urol 4: 404-6. 